\title{
Editorial
}

Psychopathology

\section{The Centennial of Karl Jaspers' General Psychopathology}

In 1913, one century ago, Karl Jaspers published the first edition of General Psychopathology. It may still be considered the most comprehensive account of psychopathology to date and has exerted a lasting influence on the development of psychiatry. After one century, many of the concepts and challenges addressed by Jaspers are still at issue. Methodological topics like understanding and incomprehensibility, and clinical issues such as defining delusions or self-awareness and its disorders are at the core of 21 st century research in psychopathology. In the course of the international renaissance of the philosophy of psychiatry in the last decade, Jaspers' early psychopathological work has again moved to the center of interest, which becomes manifest through a number of international conferences and edited volumes that celebrate its centenary [1-3].

When Jaspers entered the field of psychiatry at the beginning of the 20th century, the discipline largely conformed to the natural scientific paradigm that had reigned triumphant in the whole field of medicine since 1850. It concentrated on the search for somatic causes of mental illnesses. To do so, research was promoted above all in the areas of neuroanatomy, neurohistology, neurophysiology, and neuropathology. The majority of psychiatrists considered the psyche and psychology as things that had been supplanted by physiology. In fact, Theodor Meynert rejected the expression of 'mental illnesses' completely and spoke of psychiatry only as a 'clinic for illnesses of the forebrain' [4].

\section{KARGER}

E-Mail karger@karger.com

www.karger.com/psp
For Jaspers, this kind of psychiatric reductionism corresponded to the scientific longing for explanations, but it ignored the question of what in favor of the question of why, and thus neglected the careful description and understanding of pathological variations of psychic life. By contrast, psychopathology as a science was based for Jaspers on the assumption that even mental abnormalities have gestalt-like and meaningful characteristics and therefore cannot be explained exhaustively by the listing of symptoms; nor does a mere symptomatology provide a sufficient basis for therapy. In contrast to neurology, which correlates single deficiencies with localized physical lesions, psychopathology begins there where both the holistic structure of the mental and, as a result, the constitution of experiencing world and self as a whole suffers from a disturbance. This disturbed constitution cannot be described any longer by reference to single symptoms, but rather requires a phenomenological presentation of the whole structure of the patient's experienced world. Only if this task is accomplished can the search commence for the causes of disturbances, whether they are of a physical, biographical, social, or multicausal sort namely, by working out from a methodologically secured foundation.

These assumptions of Jaspers still offer a challenge to psychiatry in a time of growing dominance of neurobiological explanations and an often deplored decline of psychopathological research and expertise. On the other hand, Jaspers never argued for a seclusion of psychopa-

Prof. Dr. Dr. Thomas Fuch

Psychiatrische Klinik, Ruprecht-Karls Universität Vossstrasse 4

DE-69115 Heidelberg (Germany)

E-Mail thomas.fuchs@urz.uni-heidelberg.de 
thology from neurobiological progress. On the contrary, for him both were scientific approaches in their own right. Even more today, one can argue that it is only through a continuous dialogue of phenomenological, subject-oriented, and neurobiological approaches that psychiatry may advance in its knowledge, its understanding, and its explanations.

This special issue of Psychopathology appears in honor of the founder of psychopathology as a science in its own right, with its own object and its peculiar methodology. It highlights some of Jaspers' central ideas and concepts from the point of view of modern research paradigms in philosophy, psychiatry, and neuroscience. The topics range from methodological questions such as multiperspectivity, understanding, and empathy, to the psychopathology of schizophrenia, and finally to existential concepts of mental illness and psychotherapy, indicating the breadth of ideas and topics opened up by General Psychopathology.
We are looking forward to the next hundred years of fruitful psychopathological theory and research in the spirit that Karl Jaspers has brought to psychiatry.

Thomas Fuchs, Heidelberg

Sabine Herpertz, Heidelberg

References

1 Stanghellini G, Fuchs T (eds): One Century of Karl Jaspers' General Psychopathology. Oxford, Oxford Unversity Press, 2013.

2 Breyer T, Fuchs T, Mundt C (eds): Karl Jaspers' Philosophy and Psychopathology. New York, Springer, 2013.

3 Fuchs T, Micali S, Wandruszka B (eds): Karl Jaspers - Phänomenologie und Psychopathologie. Freiburg, Alber, 2013.

4 Meynert T: Psychiatrie. Klinik der Erkrankungen des Vorderhirns begründet auf dessen Bau, Leistungen und Ernährung. Wien, Braumüller, 1884 